Supporting Information

\title{
Comparative Virtual and Experimental High-Throughput Screening for Glycogen Synthase Kinase-3 $\beta$ Inhibitors
}

Tímea Polgár, Andrea Baki, Györgyi I. Szendrei and György M. Keserü* 
Brief description of the assays used for checking promiscuous inhibitors

Asp protease assay

Inhibition of the $\beta$-secretase activity was measured by PanVera's BACE fluorescence

resonance energy transfer assay kit as described in the protocol

(www.invitrogen.com/content/sfs/panvera/L0724.pdf).

Glu receptor assay

Inhibition of an undisclosed metabotropic Glu receptor activity was measured in a radioligand binding assay using native rat cortical membranes. The principle of the assay is similar to that reported by Takeuchi et al. (Z. Naturforsch. 2001, 57c, 348-355).

Peptidergic GPCR assay

Inhibition of an undisclosed peptidergic GPCR activity was measured in an intracellular $\mathrm{Ca}^{2+}$ assay using $\mathrm{CHO}$ cells stably expressing the target. The principle of the assay is similar to that reported by Simpson et al. (Eur. J. Pharmacol. 2000, 392, 1-9). 


\section{Figure S1}

The relationship between luminescent signal measured (RLU: relative light units) and the ATP concentration in the reaction buffer. The correlation coefficient $\left(R^{2}\right)$ is 0.9997 . Serial dilutions of ATP: $0.003 ; 0.01 ; 0.03 ; 0.1 ; 0.3 ; 1 ; 3 \mu \mathrm{M}$. Luminescence was recorded 10 minutes $(\boldsymbol{\bullet}), 20$ minutes $(\bullet)$ and 100 minutes $(\boldsymbol{\Delta})$ after adding the Kinase-Glo ${ }^{\mathrm{TM}}$ reagent.

Figure S2

ATP-luminescence standard curve. Concentrations of ATP: 0.06; 0.1;0.3;0.6; $1 \mu \mathrm{M}$, in the excessof substrate, $20 \mathrm{ng}$ GSK-3 $\beta$ in final volume of $40 \mu \mathrm{l}\left(30^{\circ} \mathrm{C}\right.$ and 30 minutes $)$. Control samples were measured in the same reaction mixture and under the same reaction conditions

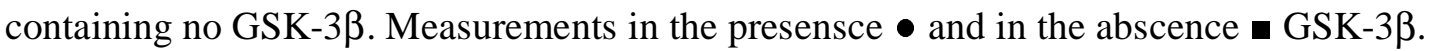

Figure S3

Determining the optimal substrate concentration. Substrate concentrations: $1 ; 5 ; 25 ; 50 ; 100$; $200 \mu \mathrm{M}$. The blank samples contained the same amount of substrate and ATP without GSK-

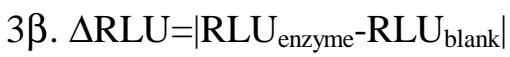

Figure S4

The optimal GSK-3 $\beta$ concentration was determined in the presence of $1 \mu \mathrm{M}$ ATP and $25 \mu \mathrm{M}$ substrate. The enzyme concentration was $2 ; 5 ; 10 ; 20 ; 40 \mathrm{ng}$. The blank values contain the same amount of ATP and substrate without GSK-3 $\beta . \Delta R L U=\left|R L U_{\text {enzyme }}-R_{L} U_{\text {blank }}\right|$

Table S1

Inhibition $\%$ of GSK-3 $\beta$ hits (as measured at concentration indicated in parenthesis) in three different assay systems

Table S2

Enrichment factors calculated at 1,2, 5 and $10 \%$ of the ranked database for enrichment studies and virtual screening of the corporate sublibrary 


\section{Figure S1}

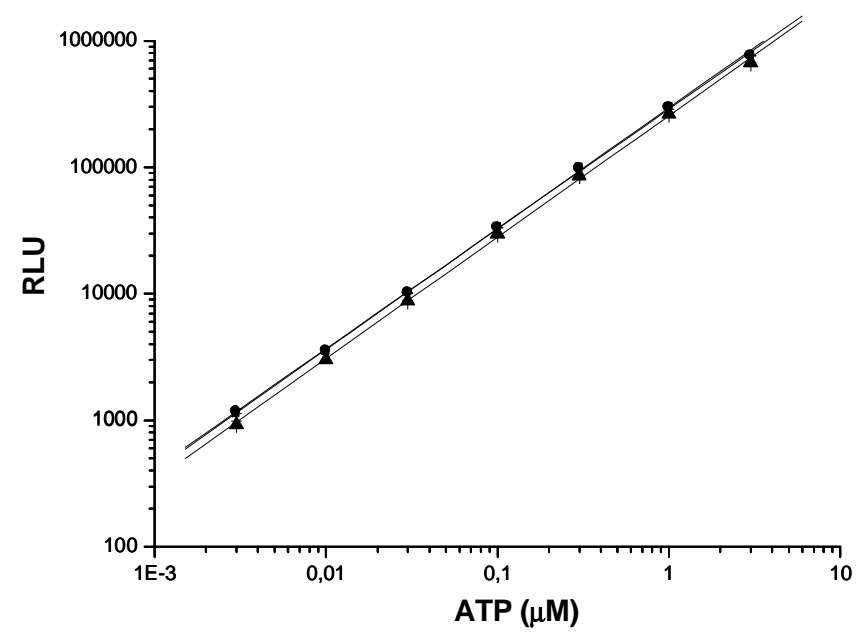

Figure S2

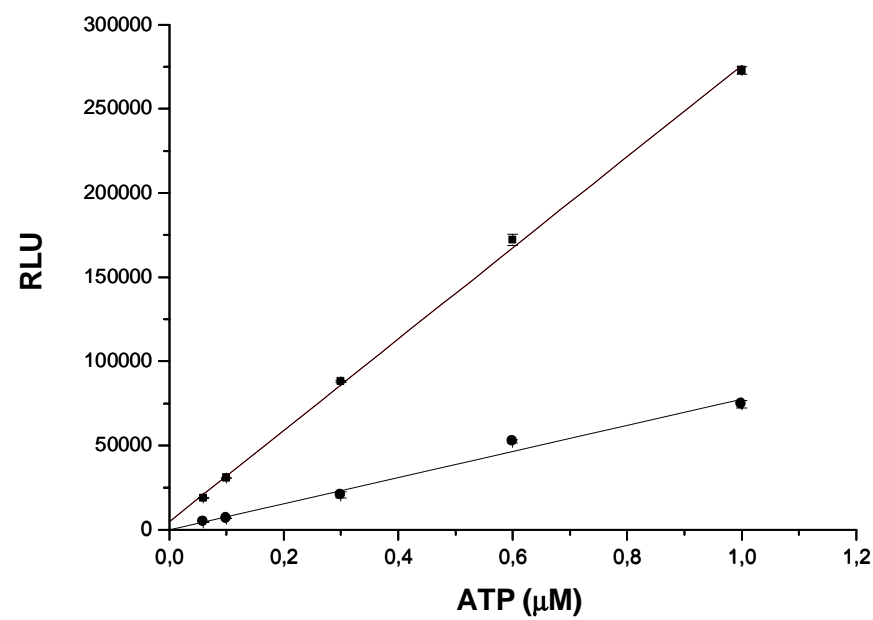


Figure S3

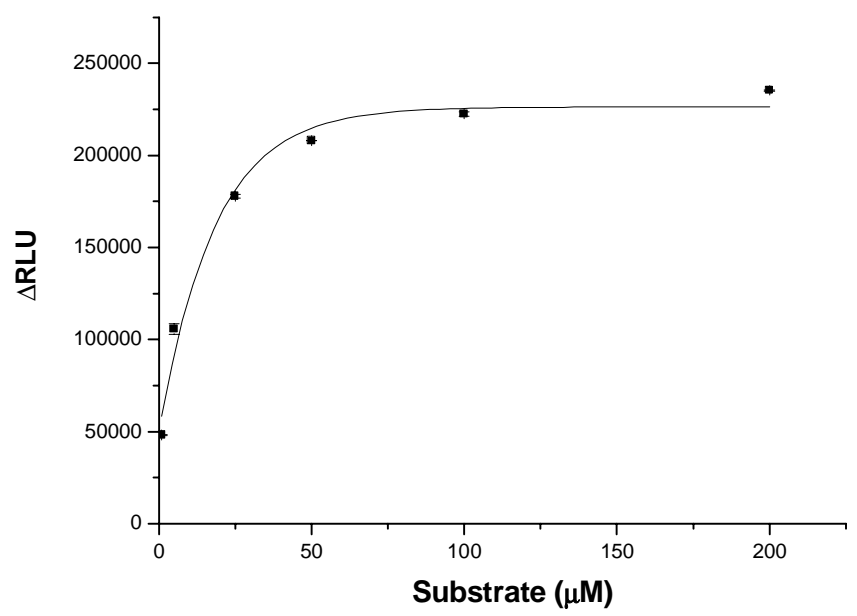

Figure S4

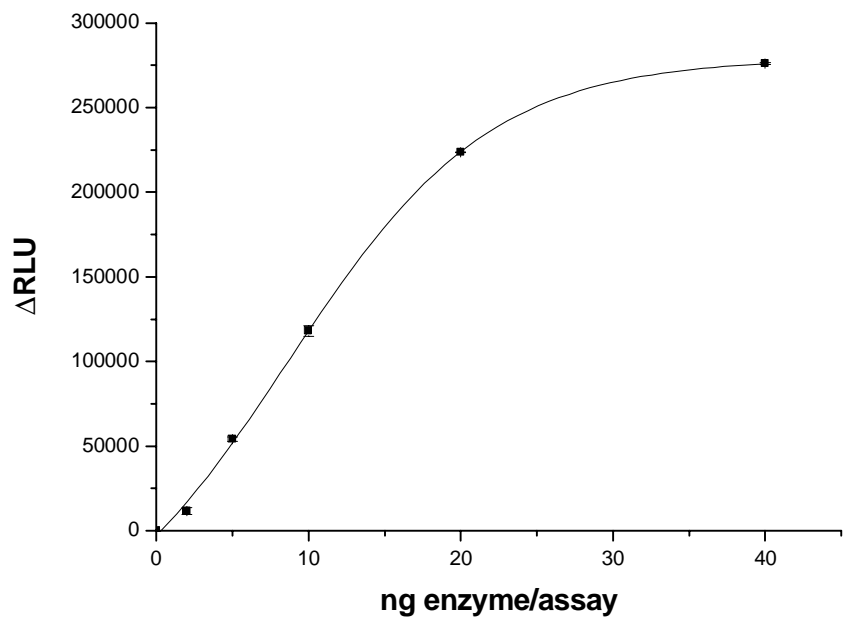




\section{Table S1}

\section{Inhibition \%}

Asp protease $(30 \mu \mathrm{M})$ Glu receptor $(10 \mu \mathrm{M})$ Peptidergic GPCR $(5 \mu \mathrm{M})$

\begin{tabular}{|c|c|c|c|}
\hline Compound 1 & 33 & $<30$ & $<30$ \\
\hline Compound 2 & $<30$ & 56 & $<30$ \\
\hline Compound 3 & $<30$ & $<30$ & $<30$ \\
\hline Compound 4 & $<30$ & $<30$ & $<30$ \\
\hline Compound 5 & $<30$ & $<30$ & $<30$ \\
\hline Compound 6 & $<30$ & $<30$ & $<30$ \\
\hline Compound 7 & $<30$ & $<30$ & $<30$ \\
\hline Compound 8 & $<30$ & $<30$ & $<30$ \\
\hline Compound 9 & $<30$ & $<30$ & $<30$ \\
\hline Compound 10 & $<30$ & $<30$ & $<30$ \\
\hline Compound 11 & $<30$ & $<30$ & $<30$ \\
\hline Compound 12 & $<30$ & $<30$ & $<30$ \\
\hline Compound 13 & $<30$ & $<30$ & $<30$ \\
\hline Compound 14 & $<30$ & $<30$ & $<30$ \\
\hline Compound 15 & $<30$ & $<30$ & $<30$ \\
\hline Compound 16 & $<30$ & $<30$ & $<30$ \\
\hline Compound 17 & $<30$ & $<30$ & $<30$ \\
\hline Compound 18 & $<30$ & $<30$ & $<30$ \\
\hline Compound 19 & $<30$ & $<30$ & 70 \\
\hline Compound 20 & $<30$ & 34 & $<30$ \\
\hline Compound 21 & $<30$ & $<30$ & $<30$ \\
\hline
\end{tabular}




\begin{tabular}{|c|c|c|c|}
\hline Compound 22 & $<30$ & 47 & $<30$ \\
\hline Compound 23 & $<30$ & 44 & $<30$ \\
\hline Compound 24 & $<30$ & $<30$ & $<30$ \\
\hline Compound 25 & $<30$ & $<30$ & $<30$ \\
\hline Compound 26 & 104 & 44 & $<30$ \\
\hline Compound 27 & $<30$ & $<30$ & $<30$ \\
\hline Compound 28 & $<30$ & $<30$ & $<30$ \\
\hline Compound 29 & $<30$ & $<30$ & $<30$ \\
\hline Compound 30 & $<30$ & $<30$ & $<30$ \\
\hline Compound 31 & $<30$ & $<30$ & $<30$ \\
\hline Compound 32 & $<30$ & $<30$ & $<30$ \\
\hline Compound 33 & $<30$ & $<30$ & $<30$ \\
\hline Compound 34 & $<30$ & $<30$ & $<30$ \\
\hline Compound 35 & 57 & $<30$ & $<30$ \\
\hline Compound 36 & $<30$ & $<30$ & $<30$ \\
\hline Compound 37 & $<30$ & 42 & $<30$ \\
\hline Compound 38 & $<30$ & $<30$ & $<30$ \\
\hline Compound 39 & $<30$ & $<30$ & $<30$ \\
\hline Compound 40 & $<30$ & 42 & $<30$ \\
\hline Compound 41 & $<30$ & $<30$ & $<30$ \\
\hline Compound 42 & $<30$ & $<30$ & $<30$ \\
\hline Compound 43 & $<30$ & $<30$ & $<30$ \\
\hline Compound 44 & $<30$ & $<30$ & $<30$ \\
\hline Compound 45 & $<30$ & $<30$ & $<30$ \\
\hline Compound 46 & $<30$ & $<30$ & $<30$ \\
\hline
\end{tabular}




\begin{tabular}{|c|c|c|c|}
\hline Compound 47 & $<30$ & $<30$ & $<30$ \\
\hline Compound 48 & 32 & $<30$ & $<30$ \\
\hline Compound 49 & $<30$ & 32 & $<30$ \\
\hline Compound 50 & $<30$ & 33 & $<30$ \\
\hline Compound 51 & $<30$ & 25 & $<30$ \\
\hline Compound 52 & $<30$ & $<30$ & $<30$ \\
\hline Compound 53 & $<30$ & $<30$ & $<30$ \\
\hline Compound 54 & $<30$ & $<30$ & $<30$ \\
\hline Compound 55 & $<30$ & $<30$ & $<30$ \\
\hline Compound 56 & $<30$ & $<30$ & $<30$ \\
\hline Compound 57 & 58 & $<30$ & $<30$ \\
\hline Compound 58 & $<30$ & 60 & $<30$ \\
\hline Compound 59 & $<30$ & $<30$ & $<30$ \\
\hline Compound 60 & $<30$ & $<30$ & $<30$ \\
\hline Compound 61 & $<30$ & $<30$ & $<30$ \\
\hline Compound 62 & N/A & $<30$ & $<30$ \\
\hline Compound 63 & N/A & $<30$ & $<30$ \\
\hline Compound 64 & $<30$ & $<30$ & $<30$ \\
\hline Compound 65 & $<30$ & $<30$ & $<30$ \\
\hline Compound 66 & $<30$ & $<30$ & $<30$ \\
\hline Compound 67 & $<30$ & $<30$ & $<30$ \\
\hline Compound 68 & $<30$ & $<30$ & 77 \\
\hline Compound 69 & $<30$ & $<30$ & 76 \\
\hline Compound 70 & $<30$ & $<30$ & $<30$ \\
\hline Compound 71 & $<30$ & $<30$ & $<30$ \\
\hline
\end{tabular}




\begin{tabular}{|c|c|c|c|}
\hline Compound 72 & $<30$ & $<30$ & $<30$ \\
\hline Compound 73 & N/A & $<30$ & $<30$ \\
\hline Compound 74 & $<30$ & $<30$ & $<30$ \\
\hline Compound 75 & $<30$ & $<30$ & $<30$ \\
\hline Compound 76 & $<30$ & $<30$ & $<30$ \\
\hline Compound 77 & $<30$ & $<30$ & $<30$ \\
\hline Compound 78 & $<30$ & $<30$ & $<30$ \\
\hline Compound 79 & $<30$ & $<30$ & $<30$ \\
\hline Compound 80 & $<30$ & $<30$ & $<30$ \\
\hline Compound 81 & $<30$ & $<30$ & $<30$ \\
\hline Compound 82 & $<30$ & $<30$ & $<30$ \\
\hline Compound 83 & $<30$ & $<30$ & $<30$ \\
\hline Compound 84 & $<30$ & $<30$ & $<30$ \\
\hline Compound 85 & $<30$ & $<30$ & $<30$ \\
\hline Compound 86 & $<30$ & $<30$ & $<30$ \\
\hline Compound 87 & $<30$ & $<30$ & $<30$ \\
\hline Compound 88 & $<30$ & $<30$ & $<30$ \\
\hline Compound 89 & $<30$ & $<30$ & $<30$ \\
\hline Compound 90 & $<30$ & $<30$ & $<30$ \\
\hline
\end{tabular}


Table S2

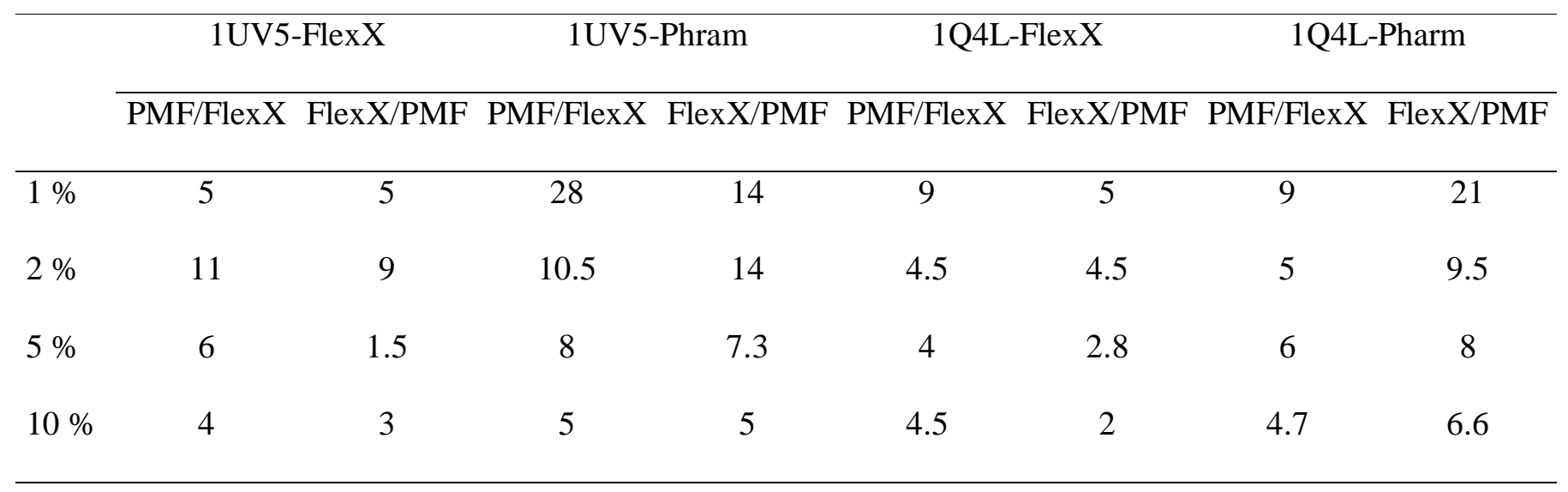

\begin{tabular}{cccccc}
\hline & \multicolumn{2}{c}{ 1Q3D-FlexX } & \multicolumn{2}{c}{ 1Q3D-Phram } & VS-Pharm \\
\cline { 2 - 6 } & PMF/FlexX & FlexX/PMF & PMF/FlexX & FlexX/PMF & PMF/FlexX \\
\hline $1 \%$ & 5 & 5 & 19 & 14 & 23 \\
$2 \%$ & 9 & 4.5 & 11.5 & 10 & 11 \\
$5 \%$ & 6 & 2.5 & 5 & 10 & 5 \\
$10 \%$ & 4 & 2.2 & 3.6 & 10 & 3 \\
\hline
\end{tabular}

